\title{
Zur Erinnerung an Lelio Basso
}

Der nachfolgende Aufsatz von Oskar Negt ist für die Festschrift für Lelio Basso anläßlich seines 75. Geburtstages geschrieben worden. Am 16. Dezember, als Lelio Basso im Kapitol in Rom die Festschrift im Beisein von Bürgermeister Argan und Parlamentspräsident Ingrao überreicht werden sollte, ist er an einem Herzversagen gestor. ben.

Lelio Basso hat für die westdeutsche Linke eine große Bedeutuing gehabt. In den 60 er Jahren, noch vor der Studentenrevolte, war die won ihm in drei Sprachen (italienisch, englisch, französisch) herausgegebene Zeitschrift „Problemi del Socialismo" für die kleine, aus der SPD herrusgedrängte, aber noch keine eigene Identität habende Linke in der Bundesrepublik ein wichtiger Mittler zur internationalen marxistischen Theorie- und Strategiediskussion. Seine Beiträge auf den Konferenzen des "Sozialistischen Bundes" und des Sozialistischen Deutschen Studentenbundes (SDS) noch yor dem 2. Juni 1967 haben in der durch Wirtschaftswunder und Antikommunismus der gerade zu Ende gehenden Adenauer-Ära sterilisierten Atmosphäre (auch an den Universitäten) eine wesentliche Rolle für den politischen Entwicklungsprozeß der Linken gespielt. Auch die Studien Bassos über Rosa Luxemóurg (in Italien hat er bei Editori Riuniti das Werk Rosa Luxemburgs hrrausgegeben) haben die politischen Diskussionen um eine Strategie der Arbeiterbewegung in der $B R D$ wesentlich beeinflußt (Lelio Basso, Rosa Luxemburgs Dialektik der Revolution, Frankfurt/M. 1967).

Im Jahre 1903 geboren, hat sich Lelio Basso als 19-jähriger, also noch vor der faschistischen Machtergreifung, der Sozialistischen Partei angeschlossen. Er wurde Mitarbeiter an der Zeitschrift ,Critica Sociale" von Turati und nach dem ,Marsch auf Rom" an einer Reihe von Oppositionszeitungen. Unter dem Faschismus wurde er zwei Mal verhaftet, zuletzt im März 1940 und in das Konzentrationslager Colfiorito (in der Nähe von Perugia) geworfen. Dort konnte er im Oktober 1940 befreit werden. Ab 1942 hatte er Verbindungen zur Resistenza, der Widerstandsbewegung gegen den Faschismus. Nachdem er 1943 führend an der Gründung des „Movimento di Unita Proletaria" (Bewegung der proletarischen Einheit) beteiligt gewesen ist, wirkte er in Mailand als dessen Vertreter in der antifaschistischen Opposition mit. Nach der Vereinigung von Sozialistischer Partei und der Bewegung der Proletarischen Einheit zur PSIUP gehört er dem Vorstand an. Die Partei existiert nicht lange, in ihr sind zu kontroverse Positionen zusammengefaßt, als daß ihr eine einheitliche Strategiefindung gelingen könnte. Bassos Weg wird bis in die späten 60er Jahre zum exemplarischen Fall für die Entwicklung des sozialistischen Flügels der italienischen Arbeiterbewegung: Spaltungen und Neugründungen, politische Konflikte sind dafür kennzeichnend: 1943 gerät Basso mit Nenni in Konflikt, der nur durch Intervention des gegenwärtigen italienischen Staatspräsidenten Pertini geregelt werden kann. 1945 geht Basso in den Vorstand der PSI und wird ein Jahr später von der Partei in die Verfassunggebende Versammlung geschickt. 1953 verliert Basso alle 
seine Parteiämter, um 1955 wieder ins Zentralkomitee gewählt zu werden. Als dann nach der Bildung des „Centro Sinistra", d.h. der Koalition zwischen Christdemokratie und Sozialisten, im Januar 1964 die PSIUP gegründet wird, wird Basso Präsident der Partei bis 1968, also bis zur erneuten Spaltung (ein Teil geht zur PSI zurück, ein zweiter Teil nähert sich der KPI an und ein dritter Teil gründet die PdUP, die dann Mitte der 70er Jahre mit der Manifesto-Gruppe (die 1969 als Abspaltung von der $K P I$ entsteht) zusammengeht. Seine letzte Position im parlamentarisch-politischen Leben erwirbt Baso als Mitglied des italienischen Senats, gewählt als Unabhängiger auf der Liste der KPI.

Anfang der 70er Jahre entzieht sich Basso bewußt den Konflikten und Querelen in der Parteienlandschaft. Er gründet das ISSOCO, das ,Institut für das Studium der gegenwärtigen Gesellschaft", auch aus der Erkenntnis heraus, daß durch die seit 1968 auflebenden Klassenkämpfe in Italien ein erneuter Versuch der parteiorganisatorischen Strukturierung der Massenbewegungen außerhalb der bestehenden Parteien notwendig zum Scheitern verurteilt sein muß. Mit dem ISSOCO versucht Basso vielmehr, unter Bezug auf die gegenwärtigen Klassenkämpfe deren sozialgeschichtliche Dimension bewußt zu machen. Die seit 1973 regelmäßig veranstalteten internationalen Studienwochen des ISSOCO hatten denn auch Themenschwerpunkte aus der Geschichte der Arbeiterbewegung. Nicht zufällig wurde zuerst über Rosa Luxemburg diskutiert (1973). Tagungen über die Marxsche und marxistische Staatstheorie, über die Aktualität der Marxschen Kritik am Gothaer Parteiprogramm folgten. Für 1979 wurde noch mit Lelio Basso gemeinsam die vierte Studienwoche über Engels" Anti-Dühring vorbereitet. In weniger großem Rahmen veranstaltet das ISSOCO Seminare über Probleme der Sozialgeschichte der Arbeiterbewegung und neuerdings auch der Frauenbewegung. Die seit 1958 von Basso herausgegebene Zeitschrift „Problemi del Socialismo“, die seit 1972 im Rahmen der ISSOCO gemacht wird, ist zu einem der wichtigen italienischen Diskussionsforen der Linken geworden.

Um der Persönlichkeit Bassos gerecht zu werden, darf nicht auf den Bericht über seine internationalen Aktivitäten verzichtet werden. Als Anwalt hat er jahrelang einige arabische Länder vor allem gegen die Öl-Multis vertreten und die Rechte der Palästinenser juristisch und politisch verteidigt. Er war während der Unidad Popular in Chile und hat dort an Universitäten Gastvorträge gehalten. Er hat aktiv am Russell-Tribunal über Lateinamerika in der internationalen Jury mitgewirkt und auch nach Beendigung des Tribunals die lateinamerikanischen Oppositionsbewegungen unterstützt und einzelnen Oppositionellen nach seinen Möglichkeiten geholfen. Es soll in diesem Zusammenhang auch nicht vergessen werden, daß Lelio Basso Mitinitiator des Komitees gegen die westdeutschen Berufsverbote in Rom gewesen ist und daß das regelmäßig erscheinende Informationsbulletin des Anti-BerufsverboteKomitees im ISSOCO gemacht wird.

Nicht nur die italienische, die internationale Linke hat mit Lelio Basso einen Genossen verloren. Die Festschrift (bei Franco Angeli in Rom 1978 erschienen) sollte die Erinnerung an ihn wachhalten. 